Martínez Barragán Carlos.

Filiación, en su caso: cargo (profesor, investigador, alumno), Universidad, Departamento, grupo.

\title{
Empatía. Principio metodológico de análisis de la representación
}

\section{Empathy. Methodological principle for analysis of representation}

TIPO DE TRABAJO: Comunicación.

PALABRAS CLAVE

Empatía, metodología, Edith Stein, prosopopeya.

KEY WORDS

Empathy, methodology, Edith Stein, prosopopoeial.

RESUMEN

Uno de los pasos necesarios para realizar Investigación Derivada de la Práctica Artística es la personificación cada elemento de la representación (en su totalidad o en partes significantes). Una vez personificados los elementos de la representación, entonces y por ello, se produce la empatía, esto es, la vivencia en el espectador del acto creativo a partir del darse de la obra. Si la vivencia de las obras (su percepción, su contemplación) es considerada como un fenómeno indubitable e incancelable (Stein 2004, pg. 21), dicha vivencia se convierte en la forma más directa de conocer la obra. De este modo, el reconocimiento del hecho creativo se da a ver en el aquí y ahora del espectador y el de la experiencia de la obra. Este trabajo recuperará la propuesta de Edith Stein y su Tesis doctoral "El problema de la Empatía. 2004" para tratar de establecer que la empatía permite vivenciar la originariedad del hecho creativo permitiendo al espectador ser consciente y, por lo tanto, ser capaz de expresar su experiencia y acercarse cognoscitivamente a lo que acontece con y en la obra de arte.

\section{ABSTRACT}

One of the necessary steps to make Art Practice as Research is the personification of each element of the representation (in its totality or in significant parts). Once the elements of the representation have been personified, empathy is produced, that is, the experience in the spectator of the creative act from the moment the work is given. If the experience of the works (their perception, their contemplation) is considered an indubitable and incancelable phenomenon (Stein 2004, pg. 21), this experience becomes the most direct way of knowing the work. In this way, the recognition of the creative fact is shown in the here and now of the spectator and the experience of the creation. This work will recover Edith Stein's proposal and her doctoral thesis "The problem of empathy. 2004 " to try to establish that empathy allows to experience the originality of the creative fact allowing the spectator to be conscious and, therefore, to be able to express his experience and to approach cognitively to what happens with and in the work of art.

\section{INTRODUCCIÓN}

1. “Principio", actitud metodológica.

Esta ponencia está basada en el concepto de empatía que Edith Stein desarrolló en su tesis doctoral a raíz de una laguna que ella detectó en las propuestas de Husserl, su director de tesis, que señala a la empatía como la forma en la que podemos superar la incapacidad de comunicar la experiencia vivida (el solipsismo trascendental) al otro, una propuesta de intersubjetividad trascendental (Infante del Rosal, 2012) que pretende ir más allá del puro reconocimiento de tipos y símbolos emocionales del otro en nuestro yo (Lipps y la propuesta sicológica de la empatía).

Cuando nos referimos a la empatía como problema cognoscitivo, necesariamente debemos abordarla desde la posición filosófica que la desarrolló con rigor, profundidad y con diversidad de obras y autores; debemos abordarla desde la fenomenología, desde la 
metodología que ha puesto como principio la consciencia presente del mundo, de las cosas y del mismo hecho de ser consciente. Presencia que es el vivenciar del yo; vivencia que es recibir lo que nos es dado a través de los sentidos. Es este hecho perceptual, el único dato indubitable que poseemos. Todo lo demás puede ser factible de poner en duda, en cuanto a su existencia, en cuanto a su duración o en cuanto a su apariencia.

Desde el vivenciar del yo, desde esa certeza, desde ese recibir lo que nos es dado, es desde donde podemos conocer al otro. Y ese darse del otro -que es el darse de uno mismo y de todo el mundo- es impulso que se encamina a terminar con la distinción, a disolver el yo y el otro en un conocimiento trascendente.

A diferencia de la sicología, la filosofía considera la empatía como un acto gnoseológico, en el que las emociones son datos que manifiestan más que los meros sentimientos y que nos llevan a cuestiones más complejas, como la consciencia del yo, la confrontación del yo con el otro, la aceptación del otro como yo y la consciencia del yo como el otro.

\section{METODOLOGÍA}

2. La metodología que seguimos en esta comunicación se aproxima a la del reduccionismo fenomenológico, trazado y empleado por la autora de referencia, Edith Stein. Pero no seguimos estrictamente la metodología reduccionista porque no dejamos al "mundo" fuera de nuestro argumento y reflexión. La percepción de la obra y de los registros intencionales y emocionales que el autor produce y deja en la obra de arte, son indispensables para nuestro razonamiento. $Y$, además, es una elección consciente ya que la obra como objeto, no sólo nos es necesaria sino querida, buscada y cuidada. No nos es suficiente el mundo indubitable de la percepción personal y la constatación de la vivencia. Si el concepto de empatía nos aporta un avance significativo en la confección de una posible metodología de la investigación derivada de la práctica artística es el hecho de que el otro es el camino del conocimiento, y el otro se personifica en la obra y por la obra.

\section{DESARROLLO}

3. Vivencia originaria y no originaria. Conocimiento del mundo por medio del reconocimiento del otro.

Las vivencias originarias y las no originarias en las que Stein basa su reduccionismo fenomenológico eidético, nos ayudarán a resolver algunas lagunas que habíamos encontrado a la hora de proponer la empatía como parte de una metodología de la investigación derivada de la práctica artística. Las vivencias originarias, las que ocurren en el presente y que son el único dato cierto que tenemos de nosotros y del mundo (Stein, 2004. p. 21) son las que se ponen en marcha en el momento de la producción de la obra. Es en el presente continuo, que se experimenta durante la creación de la obra, en el que el mundo se descubre de una forma inédita y que no es posible de acceder a él de otra forma. Los testimonios que han dejado los artistas sobre los momentos de creación son una muy buena fuente de información acerca de lo portentoso de esos momentos. El vivenciar en la creación se presenta en toda su potencia y en aspectos que se han tratado desde perspectivas diferentes. Desde la catarsis aristotélica, a la transformación de la materia (en una perspectiva marxista), pasando por el establecimiento de reglas de significación de la existencia (Dewey), hasta llegar al acto de resistencia contra la muerte de Deleuze.

Debemos señalar que aquí la vivencia originaria nos interesa porque en ella, el artista deja una serie de rastros y huellas de diferente naturaleza y niveles que permite al espectador ( $\mathrm{y}$ al creador mismo) tener la conciencia anímica del otro al alcance. Esta conciencia del otro por medio del darse en los signos es la empatía. Ampliaremos el concepto conforme vayamos examinando algunos de sus elementos constitutivos.

Ahora bien, la vivencia originaria empática una vez convertida en pasado se puede rememorar por medio de la presentificación, esto es, traer al presente cosas que existen en nuestra memoria como vivencias originarias. También es posible presentificar cosas que no han ocurrido aún, pero que son realidad vivenciada por el yo. Las fantasías no son, entonces, presentificaciones de vivencias reales, sino ... forma no originaria de vivencias presentes; teniendo en cuenta que <<presente >> no alude a un ahora del tiempo objetivo sino al ahora vivenciado que, en este caso, sólo se puede objetivar en un ahora <<neutral >> del tiempo de la fantasía. (Stein, 2004. p 26.)

Así, en el momento de la creación artística se conectan las vivencias originarias con las vivencias no originarias en diferentes niveles y con diferentes intensidades, produciendo un acto empático, de rememoración, de fantasía y culminación de la espera. Un acto complejo que, sin embargo, es posible de examinarse y analizarse. 
La empatía, al contario que el recuerdo o la fantasía, no se incluían en las acciones conscientes del acto creativo, y es este uno de los grandes apuntes que debemos a Stein al proponer a la empatía como la clave necesaria para conocer el mundo a partir de la consciencia del otro en uno mismo. Es recurrente que maestros artistas inculcaran en sus discípulos la necesidad de desarrollar la fantasía, por un lado, y que, por el otro, se cultivaran en el conocimiento de narraciones (mitología e iconografía) que sirvieran como de compendio simbólico dispuesto a ser usado, según fuera el caso. (Dentro del recuerdo también podemos situar a los conocimientos técnicos que se han adquirido en el ejercicio de un oficio como actos de vivencia originaria y que quedan latentes en la memoria y que son presentificados en el momento de la ejecución de la obra). Sin embargo, la empatía (como pathos) se recomendaba cultivar como habilidades de la locución, como una más de las cualidades morales del espíritu o una de las posibilidades de conseguir una emoción común entre todos los espectadores y no tanto como proceso de conocimiento del mundo, del otro y del yo. Tal vez por eso, Stein se aleja de la definición de Lipps que centra el acto empático en el reconocimiento de gestos simbólicos más que en el hecho de que el reconocimiento es una parte de la recepción del darse del otro. O sea, como lo hemos mencionado anteriormente, la empatía según Stein, es un acto de conocimiento profundo del mundo y no sólo saber "leer" los gestos emotivos del otro para recordarlos en nosotros mismos.

4. $\quad$ Niveles de recepción del darse del otro.

En la empatía entran en juego diferentes fenómenos complejos de los que el componente emocional es el elemento tal vez más característico. Pero esto no quiere decir que otros fenómenos se excluyan en el acto empático o que todos ocurran de la misma forma y en la misma intensidad.

Tenemos tres grados de actuación o modalidades de actuación en todos los casos considerados de presentificación de vivencias (la memoria y la espera, la empatía y la fantasía) que se corresponden a la siguiente definición: 1.0, la aparición de la vivencia; 2.0, la explicitación plenaria; 3.0, la objetivación comprehensiva de la vivencia explicitada. (Stein, 2004. p. 27)

Si seguimos el razonamiento posterior de Stein y concordamos con ella en que la explicitación plenaria es el aspecto definitorio de la empatía, también podemos ver que los otros dos niveles aparecen en todos los fenómenos empáticos. Es decir, si yo me alegro empáticamente de la alegría de otro, la alegría aparece como vivencia presente y como catapulta de vivencias pasadas traídas al momento presente. $Y$, ¿ंen qué medida son constitutivas de la vivencia? ¿El recuerdo pesa más que la vivencia originaria? $O$ ¿Es tan definitoria la experiencia "explícita plenaria" que ahoga todo recuerdo o proyección fantástica? Sabemos por vivencia propias recordadas, que lo más probable es que ocurra todo esto a la vez en niveles difícilmente determinados a posteriori. Y hasta una emoción puede estar desdibujada a tal grado que solo sea en nuestra vivencia una aproximación.

Es posible que la sonrisa de un amigo nos mueva a la alegría, aunque el motivo de su alegría sea para nosotros contrario a esa emoción y que en ese mismo momento nos invada la vergüenza por el motivo de alegría en nuestro amigo. O, al contrario, ver la tristeza de una compañera reflejada en su rostro nos puede llevar a experimentar una empatía superlativa al traer las propias vivencias y recuerdos abrumadores y superar el mismo nivel emocional de nuestra amiga. En ambos casos, somos capaces de reconocer los gestos, los ademanes y los signos que nos ofrece el otro y, al mismo tiempo, ser capaces de sumar diferentes niveles de emocionalidad y recuerdos, o proyectar fantasías

Estos diferentes niveles de intensidad y reconocimiento serán parte esencial en nuestra proposición metodológica ya que, gracias a ello, podremos crear diferentes niveles de descripciones de los diferentes aspectos de la investigación derivada de la práctica artística. Personificación de huellas y registros.

Hemos descrito la empatía en los términos que nos ayuden a establecerla como herramienta de análisis de la representación. Recordamos que nos basamos en la propuesta de Stein ya que esta nos ayuda a concebir la empatía como una herramienta metodológica en toda la extensión del término. El instrumento de análisis es congruente con su objeto de estudio, es isomórfico.

Pero para empezar a utilizar a la empatía como herramienta de análisis, antes debemos echar mano de un recurso retórico, o más bien poético, que se conecta perfectamente con la concepción fenomenológica de Stein sobre el recuerdo y la fantasía. Este recurso es la prosopopeya, recurso que ya hemos mencionado en otro trabajo anterior, pero como proyección simbólica (Martínez 2016).

La proyección simbólica que realiza el sujeto hacia el objeto y que se da gracias a que el objeto tiene una configuración específica y no otra, es lo que permite que podamos realizar una interpretación de sentido sobre el significado de nuestra percepción. Por lo tanto, la captación de la proyección es un conocimiento tanto del objeto, como del sujeto que percibe y proyecta porque sobre las proyecciones surgen elementos valorativos que sólo pueden serlo a través de la creación de juicios creados exprofeso a la situación percibida y vivida. (Martínez, 2016. p.15). 
En este documento haremos más específica dicha proyección y la nombraremos de acuerdo a su naturaleza poética, ya que nos ayudará a aclarar la presentificación de la vivencia en el acto empático que proponemos como clave del reconocimiento emocional de la obra artística.

Las vivencias originarias se quedan como asociaciones de eventos relacionados entre sí con una intensidad acorde al impacto emocional y sensitivo del evento. En las asociaciones intervienen todos los aspectos de las vivencias originarias y todos los sentidos a la vez. Cada aspecto de la vivencia originaria queda impreso en la memoria. Gestos, olores, texturas, formas, tamaños, configuraciones generales, palabras, pensamientos, símbolos visuales y auditivos, etc. conforman un sello que imprime una nota de recuerdo almacenada en la memoria. De acuerdo al impacto que todo ello ha tenido en nosotros, adquiere un sitio específico en nuestra memoria. Somos capaces de traer al presente, más o menos de manera voluntaria, aquel raudal de elementos que conforman un recuerdo significante y emocional. Y si percibimos una conjunción azarosa de elementos en un momento dado, También es posible que esa unión nos traslade a un estado emocional vivenciado.

Ahora bien, cuando realizamos una representación, imprimimos en ella elementos configurantes que responden a las intencionalidades expresivas emocionales, simbólicas e iconográficas que queremos comunicar y expresar. Esta configuración no es una simple agrupación de objetos sino una estructuración de signos que responden, entre otras cosas, a una emocionalidad concreta, emocionalidad vivencial que queda registrada en la obra.

Una vez configurada, ese registro es un objeto cargado de contenido emocional y simbólico que está expuesto a la vivencia del otro. Y es aquí en donde la prosopopeya se pone en marcha. Percibimos no solo los elementos formales de la configuración sino también la carga emocional que, de manera originaria, ha vivenciado el autor de la representación. Podemos identificar contenidos emocionales y no únicamente simbólicos o icónicos. Esta recepción del registro emocional de la obra es la que nos abre la posibilidad de un encuentro con las vivencias ajenas vivenciadas desde el interior del registro, o sea, desde la obra.

Es cuando la obra, la representación, por medio de la empatía, se convierte en un acto cognoscitivo porque a partir de él, podemos adentrarnos en el yo ajeno desde el nuestro, lo que inaugura una serie de constataciones sobre la existencia, como por ejemplo: la constatación del yo, la identificación y la asociación, la consciencia del otro como tal y en referencia a mí, la evidencia de ser el otro en cuanto a identificación, la disolución del objeto y del sujeto, el acto de presentificar emociones e intencionalidades, entre otras. Y además también podemos identificar símbolos, usos y costumbres del creador de la representación, de su momento histórico y geográfico, además de los aspectos éticos, estéticos, sicológicos, antropológicos, que se manifiesta en la obra. La empatía, a través de la personificación y con los recursos de la presentificación de los recuerdos y las fantasías, es el elemento que provoca en el espectador una revisión más afondo del simple reconocimiento de la configuración de la representación. Es la que nos induce a la investigación.

La prosopopeya resulta ser la vía de acceso al registro de la emotividad plasmada en la obra por el autor. La vivencia corporal de la experiencia es la base de toda experiencia emocional. Sin la afectación del cuerpo, la emoción se convierte en una descripción sin anclaje y en cierto sentido, sin significado. La prosopopeya de la configuración de todos los aspectos formales de la obra nos conduce a "revivir" emocionalmente el proceso creativo registrado por los materiales. $Y$ es así como nos emociona un retrato de Pinazo, un video de Viola o una instalación de On Kawara.

También la obra es un acto cognoscitivo cuando somos ajenos a las emociones que se nos presentan; entonces tenemos la oportunidad de vivenciar originariamente tales emociones, lo que le otorga a la obra una capacidad de instrucción y de revelación al espectador. Ahora bien, esto no quiere decir que experimentemos la vivencia del otro con todas sus consecuencias a través de la empatía. Recordemos que la vivencia originaria, que es la vivencia del autor que construye la representación, se da sólo en el individuo que pone en marcha todas sus capacidades para generarla. Cuando se recuerda o fantasea, en el momento en que se transfiere la emoción a la vivencia, en ese momento deja de ser emoción recordada o fantaseada y en su lugar se asienta la emoción vivencial, aunque su contenido no sea originario. Es decir, nosotros, como espectadores de dicha obra, solo vivenciamos originariamente el acto de ser espectadores, vivencia que no es para nada insignificante, pero que es de naturaleza diferente a la vivencia originaria de la creación.

\section{CONCLUSIONES}

Podemos concluir que la empatía es la capacidad de aprender, a partir de las emociones propias, la consciencia del otro por sí mismo, y el conocimiento del otro desde el yo. Es un acto cognoscitivo que va más allá del puro reconocimiento de emociones ajenas y la capacidad de vivenciarlas en nosotros. Es la forma en la que podemos entablar comunicación con el otro sobre aspectos emocionales de las vivencias, porque la experiencia del otro sobre esa vivencia emocional es capaz de lograr una verdadera comunicación. 
La obra de arte se crea mediante la configuración formal de signos y símbolos utilizando materiales de diferente naturaleza. Esta configuración la realiza el autor desde una intencionalidad específica que está imbuida de un momento emocional concreto y singular. Esa intencionalidad y emotividad se registra en la obra por medio de los materiales y la configuración particular de cada parte de la obra. Gestos, signos, símbolos, materiales y soportes se mezclan en una unión inseparable en la obra. Inseparables, pero no inidentificables. Podemos percibir cada parte de la obra y tener una conciencia aproximada de procesos, intencionalidades y emociones con las que se ha producido la obra. Y es aquí donde la empatía se expone como instrumento de conocimiento. Las emociones que imbuían al autor en el momento de la creación están registradas en la obra, pero sólo personificándola a ella y a cada una de su partes y configuraciones, en particular y en general, es como somos capaces de vivenciar el mundo emocional del autor. Lo vivenciamos de dos formas. no originariamente, desde el reconocimiento de la emotividad ajena, y originariamente, desde experiencia de la percepción de la obra. También aquí, la capacidad cognoscitiva de la empatía por medio de la prosopopeya se manifiesta ya que el espectador es capaz de aprender nuevas emociones y nuevas sutilezas de las ya conocidas, creadas por las relaciones novedosas de una obra de arte.

\section{FUENTES REFERENCIALES}

Casals, A., y Chiuminatto, P. (2017). Hablar por otros: Variaciones de la personificación en dos odas de Pablo Neruda. Nueva revista del Pacífico, 66, 29-53.

Infante del Rosal, F. (2013). Ficción en la idea de empatía de Edith Stein. Ideas y valores, 62 (153), 137-155.

Martínez B. C. (2016). Herramientas cualitativas derivadas de la inteligencia emocional para la investigación en Bellas Artes. En V Encuentro Latinoamericano de Metodología de las Ciencias Sociales (ELMeCS) Métodos, metodologías y nuevas epistemologías en las ciencias sociales: desafíos para el conocimiento profundo de Nuestra América. Mendoza, FCPYS-UNCUYO. Recuperado de http://elmecs.fahce.unlp.edu.ar - ISSN 2408-3976 (pág. 2).

Ricoeur, P. (2000). Narratividad, fenomenología y hermenéutica. Anàlisi: quaderns de comunicació i cultura, 25, 189-207.

Stein, E., y Bono, J. L. C. (2004). Sobre el problema de la empatía. Editorial Trotta. 